\title{
ITRAQ-based comparative proteomic analysis of cells infected with Eimeria tenella sporozoites
}

\author{
Zongping Zhao, Qiping Zhao, Shunhai Zhu, Bing Huang, Ling Lv, Ting Chen, Ming Yan, Hongyu Han*, and Hui Dong*
}

Key Laboratory of Animal Parasitology of Ministry of Agriculture, Shanghai Veterinary Research Institute, Shanghai 200241, PR China

Received 1 August 2018, Accepted 11 February 2019, Published online 20 February 2019

\begin{abstract}
Eimeria tenella is an obligate intracellular parasite that actively invades cecal epithelial cells of chickens. When E. tenella infects a host cell, the host produces a corresponding change to deal with damage caused by this infection. To date, our knowledge on the mechanism of how the host cell responds to E. tenella infection is highly limited at both the molecular and cellular levels. In this study, isobaric tags for relative and absolute quantitation (iTRAQ) coupled with LC-MS/MS was used to screen the differentially expressed proteins (DEPs) in BHK-21 cells infected with E. tenella sporozoites for $24 \mathrm{~h}$ post infection. In total, 6139 non-redundant distinct proteins were identified and 195 of these were found to have a fold change ratio $\geq 1.3$ or $\leq 0.7$ and $p<0.05$, including 151 up-regulated proteins and 44 down-regulated proteins. The reliability of the proteomic data was further validated with qPCR and western blot. Gene Ontology enrichment indicated that the up-regulated DEPs were mainly involved in binding and catalytic activity, whereas the down-regulated DEPs were catalytic activity and molecular function regulators. Furthermore, KEGG pathway analysis showed that the DEPs participated in the PI3K-Akt, chemokine, Ras, Wnt, and p53 signaling pathways and so on, and the up-regulated and down-regulated DEPs mainly related to the ribosome and mRNA surveillance pathway, respectively. The data in this study provide an important basis to further analyze E. tenella host cell interactions.
\end{abstract}

Key words: iTRAQ, Eimeria tenella, Sporozoites, BHK-21 cells, Differentially expressed proteins.

\begin{abstract}
Résumé - Analyse protéomique comparative basée sur iTRAQ de cellules infectées par les sporozoïtes d'Eimeria tenella. Eimeria tenella est un parasite intracellulaire obligatoire qui envahit activement les cellules épithéliales cæcales des poulets. Quand E. tenella infecte une cellule, l'hôte produit un changement correspondant pour traiter les dommages causés par cette infection. À ce jour, nos connaissances sur le mécanisme de réponse de la cellule hôte à l'infection à E. tenella sont très limitées, tant au niveau moléculaire que cellulaire. Dans cette étude, des marqueurs isobares pour la quantification relative et absolue (iTRAQ) couplés à la LC-MS / MS ont été utilisés pour cribler les protéines exprimées de manière différentielle (PED) dans des cellules BHK-21 infectées par des sporozoïtes de E. tenella, $24 \mathrm{~h}$ après l'infection. Au total, 6139 protéines distinctes non redondantes ont été identifiées, et 195 d'entre elles présentaient un taux de variation de $\geq 1,3$ ou $\leq 0,7$ et un $p<0,05$, dont 151 protéines régulées positivement et 44 protéines régulées négativement. La fiabilité des données protéomiques a ensuite été validée avec qPCR et Western Blot. L'enrichissement par l'ontologie des gènes a indiqué que les PED régulés positivement étaient principalement impliquées dans la liaison et l'activité catalytique, alors que les PED régulées négativement étaient celles de l'activité catalytique et des régulateurs de la fonction moléculaire. De plus, l'analyse de la voie de KEGG a montré que les PED participaient aux voies de signalisation de PI3K-Akt, de la chémokine, de Ras, de Wnt, de p53, et autres, et que les PED régulées positivement et négativement étaient liées respectivement aux voies de surveillance du ribosome et de l'ARNm, respectivement. Les données de cette étude fournissent une base importante pour une analyse plus poussée des interactions entre les cellules hôtes d'E. tenella.
\end{abstract}

\section{Introduction}

Coccidiosis of the chicken is caused by the genus Eimeria and is one of the most common and serious diseases on farms worldwide [14]. Coccidiosis causes serious economic losses in poultry farming [25]. Currently, the prevention and control of chicken coccidiosis mainly relies on anti-coccidial drugs, but drug-resistance has become an unavoidable problem. Therefore, there is an urgent need to find new measures to control chicken coccidiosis $[24,30]$.

\footnotetext{
*Corresponding authors: hhysh@shvri.ac.cn; donghui@shvri.ac.cn
} 
Eimeria has a complex life cycle and its development and reproduction depend on the intestinal epithelium of chickens. The invasion of host intestinal epithelium by Eimeria species is a complex, multistep process. It starts with the adhesion of the parasite to the host cell. Then by quick invasion, it takes the shape of an intracellular, parasitophorous vacuole that surrounds the newly invading parasite, ensuring its survival within the host [27]. In order to perpetuate the infection, Eimeria first egress from infected cells and then reinvade uninfected cells. Faced with these circumstances, host cells have formed their own regulatory mechanisms to cope with these changes and invasion. Specifically, the expression of IDO1 (indoleamine 2,3-dioxygenase1) in the host epithelial cells increases after being infected with $E$. falciformis and this level of expression remains during the entire infection with the parasite. This response plays a vital role in maintaining the parasite at optimal development [22]. Additionally, $F$-actin has been shown to accumulate in human HCT-8 ileocecal adenocarcinoma cells after being infected with $E$. tenella, and plays a positive role in parasitic invasion [32]. Furthermore, chicken Toll-like receptor 4 (ChTLR4) and ChTLR15 have been shown to be up-regulated and involved in the recognition of E. tenella after infection [36]. Taken together, these results show that Eimeria have the ability to reprogram host cell response for their survival and reproduction. However, the extent and relevance of Eimeria-mediated host responses remains poorly studied.

Isobaric tags for relative and absolute quantitation (iTRAQ) in combination with liquid chromatography tandem mass spectrometry (LC-MS/MS) analysis have become an important quantitative proteomic method with certain advantages over traditional proteomic techniques. These advantages include higher throughput, increased sensitivity, and greater accuracy. This technique has been used successfully to explore pathogen-host interactions for both viruses [7] and bacteria [37]. In our study, iTRAQ was used to identify the differentially expressed proteins (DEPs) in Baby Hamster Kidney fibroblast cells (BHK-21) infected with E. tenella sporozoites.

\section{Materials and methods \\ Ethics statement}

All animal procedures were ratified by the Animal Ethics Committee of the Shanghai Veterinary Institute, Chinese Academy of Agricultural Science. Experiments were carried out according to animal ethics guidelines and approved protocols.

\section{Parasite and cell culture of BHK-21}

The Shanghai strain of E. tenella was isolated from a sample collected on a chicken farm in Shanghai, China, and has been retained in our laboratory since 1993. E. tenella was propagated by means of coccidia-free 2 -week-old chickens, as described previously [29]. Sporozoites were prepared from cleaned sporulated oocysts by in vitro excystation and purified by chromatography over columns packed with nylon wool and DE-52 cellulose [35]. BHK-21 was cultured in Dulbecco's modified Eagle's medium (DMEM) (Life Technology, Carlsbad, CA,
USA) supplemented with $10 \%$ fetal bovine serum (FBS) at $37{ }^{\circ} \mathrm{C}$ and $5 \% \mathrm{CO}_{2}$.

\section{Sample collection}

Monolayers of BHK-21 cells $\left(1 \times 10^{6}\right.$ cell per flask) were seeded into T25 culture flasks and cultured to $80 \%$ confluence. Freshly excysted sporozoites were treated with penicillin/ streptomycin, then centrifuged at $1000 \times g$ for $5 \mathrm{~min}$, washed twice with DMEM, and quantified using a hemocytometer. The pretreated sporozoites were added to adherent cells at a ratio of two sporozoites per cell and cultured at $41{ }^{\circ} \mathrm{C}$ in $5 \% \mathrm{CO}_{2}$. At the same time, the mock-infected cell samples were set as a control group. The E. tenella- and mock-infected cells were collected at 24 hpi. Each group was treated with three independent biological replicates.

\section{Protein extraction}

The E. tenella- and mock-infected cell samples were washed with chilled phosphate-buffered saline (PBS) three times, collected with cell scrapers, and homogenized in lysis buffer (4\% SDS, 1 mM DTT, $150 \mathrm{mM}$ Tris- $\mathrm{HCl} \mathrm{pH}$ 8.0, protease inhibitor), then incubated for $3 \mathrm{~min}$ in boiling water and sonicated on ice twice, and clarified by centrifugation at $16,000 \times g$ at $25^{\circ} \mathrm{C}$ for $10 \mathrm{~min}$. Protein content was determined using the BCA protein assay reagent (Beyotime) and stored at $-80^{\circ} \mathrm{C}$ until use.

\section{Protein digestion and iTRAQ labeling}

Protein digestion was conducted by the filter-aided sample preparation (FASP) procedure described previously [31]. The acquired peptide mixture was labeled using the 8-plex iTRAQ reagent, according to the manufacturer's instructions (AB SCIEX, Foster City, CA, USA). In short, for each sample, $200 \mu \mathrm{g}$ of protein was added to $30 \mu \mathrm{L}$ SDT buffer (4\% SDS, $100 \mathrm{mM}$ DTT, $150 \mathrm{mM}$ Tris-HCl pH 8.0). DTT and other low-molecular-weight components were removed with UA buffer ( $8 \mathrm{M}$ Urea, $150 \mathrm{mM}$ Tris- $\mathrm{HCl} \mathrm{pH}$ 8.0) by repeated ultrafiltration (Pall units, $10 \mathrm{kDa}$ ). Then, $100 \mu \mathrm{L}$ iodoacetamide ( $0.05 \mathrm{M}$ in UA) was added to the sample to block reduced cysteine residues and incubated for $20 \mathrm{~min}$ in darkness. The filters were washed with $100 \mu \mathrm{L}$ of UA buffer three times, and then with $100 \mu \mathrm{L}$ DS buffer (50 mM triethylammonium bicarbonate at $\mathrm{pH}$ $8.5)$ twice. Finally, the protein suspensions were digested with $2 \mu \mathrm{g}$ trypsin (Promega, Madison, WI, USA) in $40 \mu \mathrm{L}$ DS buffer overnight at $37^{\circ} \mathrm{C}$ and the resulting peptides were collected as a filtrate. The peptide content was estimated with UV light spectral density at $280 \mathrm{~nm}$ using an extinction coefficient of 1.1 for a $0.1 \%(\mathrm{~g} / \mathrm{L})$ solution that was calculated on the basis of the frequency of tryptophan and tyrosine in vertebrate proteins.

For labeling, each iTRAQ reagent was dissolved in $70 \mu \mathrm{L}$ of ethanol and added to the respective peptide mixture. The mock-infected groups were labeled with iTRAQ tag 113, 114 and 115; and the E. tenella-infected groups were labeled with iTRAQ tag 116, 117 and 118. The labeled samples were incubated at room temperature for $2 \mathrm{~h}$ and then terminated, then mixed and dried with a rotary vacuum concentrator. 


\section{Peptide fractionation with strong cation exchange (SCX) chromatography}

iTRAQ labeled peptides were fractionated with SCX chromatography using the AKTA Purifier system (GE Healthcare, Chalfont Saint Giles, UK). The dried peptide mixture was reconstituted and acidified with $2 \mathrm{~mL}$ of buffer $\mathrm{A}\left(10 \mathrm{mM} \mathrm{KH}_{2} \mathrm{PO}_{4}\right.$ in $25 \% \mathrm{ACN}, \mathrm{pH}$ 2.7) and loaded onto a PolySULFOETHYL $4.6 \times 100 \mathrm{~mm}$ column $(5 \mu \mathrm{m}, 200 \AA$ A, PolyLC Inc., Maryland, $\mathrm{MD}$, USA). The flow rate was kept at $1 \mathrm{~mL} / \mathrm{min}$, the gradient program started with $0-10 \%$ buffer B $(500 \mathrm{mM} \mathrm{KCl}, 10 \mathrm{mM}$ $\mathrm{KH}_{2} \mathrm{PO}_{4}$ in $25 \% \mathrm{ACN}, \mathrm{pH} 2.7$ ) for $2 \mathrm{~min}$, followed by 10-20\% buffer B for $25 \mathrm{~min}, 20-45 \%$ buffer B for $5 \mathrm{~min}$, and $50-100 \%$ buffer B for 5 min. Eluting peptides were monitored at $214 \mathrm{~nm}$ and fractions were collected over one-minute intervals. The collected fractions (about 30 fractions) were finally combined into 10 pools and a C18 clean-up (Empore ${ }^{\mathrm{TM}} \mathrm{SPE}$ Cartridges C18 standard density, bed I.D. $7 \mathrm{~mm}$, volume $3 \mathrm{~mL}$, Sigma, Tokyo, Japan) was performed according to the manufacturer's instructions, then concentrated by vacuum centrifugation and reconstituted in $40 \mu \mathrm{L}$ of $0.1 \%(\mathrm{v} / \mathrm{v})$ trifluoroacetic acid. All samples were stored at $-80{ }^{\circ} \mathrm{C}$ until further use.

\section{Liquid chromatography (LC)-electrospray ionization tandem MS (MS/MS) analysis with $Q$ Exactive}

Experiments were performed on a $\mathrm{Q}$ Exactive mass spectrometer that was coupled to Easy nLC (Thermo Fisher Scientific, Waltham, MA, USA). Each fraction $(10 \mu \mathrm{L})$ was injected for nanoLC-MS/MS analysis. The peptide mixture $(5 \mu \mathrm{g})$ was loaded onto a C18-reversed phase column $(15 \mathrm{~cm}$ long, $75 \mu \mathrm{m}$ inner diameter) packed in-house with RP-C18 $5 \mu \mathrm{m}$ resin in buffer A $(0.1 \%$ formic acid $)$ and separated with a linear gradient of buffer B $(80 \%$ acetonitrile and $0.1 \%$ formic acid) at a flow rate of $250 \mathrm{~nL} / \mathrm{min}$ controlled by IntelliFlow technology over $60 \mathrm{~min}$. MS data were acquired using a data dependent top 10 method, dynamically choosing the most abundant precursor ions from the survey scan $(300-1800 \mathrm{~m} / \mathrm{z})$ for higher-energy C-trap dissociation (HCD) fragmentation. Determination of the target value was based on predictive automatic gain control. The dynamic exclusion duration was $60 \mathrm{~s}$. Survey scans were acquired at a resolution of 70,000 at $200 \mathrm{~m} / \mathrm{z}$ and resolution for HCD spectra was set to 17,500 at $200 \mathrm{~m} / \mathrm{z}$. Normalized collision energy was $30 \mathrm{eV}$, which specifies the minimum percentage of the target value likely to be reached at maximum fill time, and was defined as $0.1 \%$. The instrument was run with peptide recognition mode enabled. All the experiments included three biological replicates, and each contained two technical replicates.

\section{Sequence database searching and data analysis}

MS/MS spectra were searched using MASCOT engine (Matrix Science, London, UK; version 2.2) embedded into Proteome Discoverer 1.4 (Thermo Electron, San Jose, CA, USA) against the UniProt Cricetidae database (74,901 sequences, download on April 10, 2017) and the decoy database. For protein identification, the following options were used. Peptide mass tolerance $=20 \mathrm{ppm}, \mathrm{MS} / \mathrm{MS}$ tolerance $=0.1 \mathrm{Da}$, Enzyme $=$ Trypsin, Missed cleavage $=2$, Fixed modification: Carbamidomethyl (C), iTRAQ8plex (K), iTRAQ8plex (N-term), Variable modification: Oxidation $(\mathrm{M}), \mathrm{FDR} \leq 0.01$.

\section{Bioinformatics}

The Gene Ontology (GO) program Blast2GO (https://www. blast2go.com/) was used to annotate differential expression proteins to create histograms of GO annotation, including cell component, biological process, and molecular function. For pathway analysis, the differentially proteins were mapped to the terms in the KEGG (Kyoto Encyclopedia of Genes and Genomes) database by using the KAAS program (http:// www.genome.jp/kaas-bin/kaas_main).

\section{qPCR analysis}

Quantitative real-time PCR (qPCR) was employed to compare gene expression in E. tenella-infected and mock-infected cells. Total RNA was extracted with the TRIzol reagent (Invitrogen) and treated with DNase (Invitrogen). cDNA was synthesized from $2 \mu \mathrm{g}$ of total RNA by SuperScript II reverse transcriptase (Invitrogen) using random primers. Real-time PCR was performed on a Rotor-Gene 3000 (Corbett Robotics, San Francisco, CA, USA) using the SYBR1 green I dye method and specific primer sets (Table 1). The amplification reactions were performed with the following conditions: $30 \mathrm{~s}$ at $95^{\circ} \mathrm{C}$, 40 cycles of $95{ }^{\circ} \mathrm{C}$ for $5 \mathrm{~s}, 60{ }^{\circ} \mathrm{C}$ for $30 \mathrm{~s}$ and $72{ }^{\circ} \mathrm{C}$ for $30 \mathrm{~s}$. Relative transcript levels were calculated using the $2^{-\Delta \Delta \mathrm{CT}}$ method [23]. The relative expression values of the targeted gene were normalized to the expression value of the BHK-21 glyceraldehyde-3-phosphate dehydrogenase (GAPDH) gene. All the experiment included three biological replicates and each contained three technical replicates.

\section{Western blotting}

We analyzed the Lamin-B receptor (LBR) and Metastasisassociated protein MTA3 (MTA3) by western blotting because clear variation in their protein expression levels could be detected. Cell lysates for E. tenella-infected and mock-infected cultures were harvested at $24 \mathrm{hpi}$ and protein concentrations were determined using the QuantiPro ${ }^{\mathrm{TM}}$ BCA Assay Kit (Sigma), according to the manufacturer's instructions. Equivalent quantities of protein were subjected to SDS-PAGE and then transferred to polyvinylidene difluoride transfer membranes (Millipore, Boston, MA, USA). The membranes were blocked in Phosphate Buffer Solution with Tween 20 (PBST) containing $1 \% \mathrm{BSA}$ for $2 \mathrm{~h}$ at $37{ }^{\circ} \mathrm{C}$, after which they were incubated overnight at $4{ }^{\circ} \mathrm{C}$ with primary antibodies to LBR, MTA3 and $\beta$-actin (CUSABIO, Wuhan, China). The membranes were washed five times with PBST and then incubated with HRP-conjugated secondary antibodies (CUSABIO) at $37{ }^{\circ} \mathrm{C}$ for $1 \mathrm{~h}$. The membranes were washed five times and proteins were then detected using Clarity ECL reagents (Amersham Biosciences, Waukesha, WI, USA). 
Table 1. Sequence of gene-specific primers for qPCR assays.

\begin{tabular}{ll}
\hline Gene name & Primer sequence $\left(5^{\prime}-3^{\prime}\right)$ \\
\hline Atp51 & UP - AGCCTGACCTTGGAACTGGG, LP - CAGGGATTTCAGCAGGGGTT \\
Mapk9 & UP - CCCTATGTGGTGACTCGCTAT, LP - ACATAATTCCTCACGGTTGG \\
Ptp4a1 & UP - GGCTGCTGTATTGCTGTCCA, LP - CATCAGGCACCCCAGTTTTA \\
Bnip2 & UP - GCCAACCTGGCTCATTAGAA, LP - CAAATCATCCGACCACACAG \\
Pdss2 & UP - GCAGATTGGAGAGGCTCAAG, LP - CTCCAGTGCCTTGTTTCCAT \\
Ppp2r 4 & UP - TTGTGGATGAGAAGGCAGTG, LP - GGTCCACAGCTGGTTGGAGT \\
Gdil & UP - GGACAGGTCTTACCGAATGC, LP - ATGCCCATCAGATTAGAAGC \\
Sec61a1 & UP - TCAGCCCCACCACTGTCAAC, LP - TCGGAAGCCCTGGAAATAGA \\
Tm7sf2 & UP - CTCGCCTTGGTTCCTTTGAC, LP - CAGAGGGCATCACCCACATA \\
Rps8 & UP - GGGCACTCGCTACATGTTCT, LP - GCCCATTCCCTTGATGTCTA \\
Mrp120 & UP - GGAGGTGCTGAAACATGCTC, LP - GTTCCGCTTCTTCAGTCTGC \\
Tfrc & UP - CCAGTGTTGGAACAGGTCTT, LP - CTCCGAAGTCTCCTGCACTC \\
GAPDH & UP - TGTGGAAGGACTCATGACCA, LP - GGATGCAGGGATGATGTTCT \\
\hline &
\end{tabular}

\section{Results}

\section{Protein profiling of BHK-21 cells}

After processing the MS/MS spectra using Mascot software, 30,984 unique peptides were mapped to 6139 proteins from BHK-21 cells, which were assigned to 25 different GO categories. The most abundantly populated GO category with 1339 proteins was General Function (Fig. 1). Other frequently assigned categories included post-translational modification, protein turnover, chaperones (596 proteins), translation, ribosome structure, and biogenesis (585 proteins), amino acid transport and metabolism (328 proteins), and energy production and conversion (356 proteins).

\section{Protein responses to $E$. tenella infection in BHK-21 cells}

Based on a cut-off of a fold change $\geq 1.3$ or $\leq 0.7$ and a $p<0.05$ [20, 38], 195 proteins were found to be significantly changed in BHK-21 cells in response to E. tenella infection (Supplementary Table S1). This included 151 up-regulated proteins and 44 down-regulated proteins. The top five up-regulated DEPs were identified as serine/threonine-protein phosphatase 2A activator, BCL2/adenovirus E1B $19 \mathrm{kDa}$ protein-interacting protein 2, Plexin-D1, decaprenyl-diphosphate synthase subunit 2-like protein, and an uncharacterized protein. The top five down-regulated DEPs were found to be collagen alpha-1 (XXVII) chain-like protein, BAG family molecular chaperone regulator 3 , telomerase protein component 1 , and two uncharacterized proteins. Taken together, these results indicate that E. tenella invasion induced a distinct proteomic profile in BHK-21 cells, and in turn host cells sharply altered the related proteins in response to $E$. tenella infection.

All DEPs were categorized using GO analysis based on the international standardized gene functional classification system. They were found to be involved in cellular (14.34\%), metabolic $(12.71 \%)$, single-organism processes $(12.95 \%)$, and biological regulation $(9.16 \%)$ (Fig. $2 \mathrm{~A})$. Additionally, some of these proteins were predicted to be membrane associated (9.49\%), organelle associated $(16.25 \%)$ and involved in macromolecular complexes $(8.17 \%)$ (Fig. 2B). Moreover, proteins were assigned to structural molecule activity $(6.76 \%)$, involved in binding (46.62\%), catalysis $(27.34 \%)$, transport (4.18\%), molecular function regulator $(6.76 \%)$, and transporter activity (5.07\%) (Fig. 2C).

Likewise, the significantly up- and down-regulated DEPs were also annotated with GO analysis. Interestingly, the proteins assigned to biological process and cellular component for the up-regulated proteins were similar to those assigned to the down-regulated DEPs. The three main biological process groups that the proteins identified were assigned to were cellular process, single-organism process, and metabolic process (Fig. 3A). Additionally, the cellular component groups assigned to both the up- and down-regulated proteins were membrane, organelle part and organelle (Fig. 3B). However, there are some differences in the molecular function between the up-regulated and down-regulated proteins. The up-regulated proteins were found to be mainly involved in binding and catalytic activity, while down-regulated proteins were found to be related to catalytic activity and molecular function regulators (Fig. 3C).

The KEGG pathway analysis for the DEPs showed that they were involved in the PI3K-Akt, chemokine, RIG-I receptor-mediated phagocytosis, Ras, Wnt, and p53 signaling pathways. However, a significant difference in the KEGG pathways identified was found between the up-regulated and down-regulated proteins; most of the up-regulated DEPs were associated with the ribosome and the down-regulated DEPs were mainly associated with the mRNA surveillance pathway (Fig. 4).

\section{Validation of protein identification and quantification with qPCR and western blot}

To confirm the reliability of the iTRAQ results, 12 proteins were selected for confirmation using qPCR including six upregulated ones and six down-regulated ones and two proteins by immunoblotting analysis, including one up-regulated one and one down-regulated one.

The mRNA expression levels detected with qPCR were consistent with those obtained by iTRAQ for 10 proteins including Atp51 (ATP synthase), Mapk9 (Mitogen-activated protein kinase 9), Pdss2 (Prenyl diphosphate synthase, subunit 2), Ppp2r4 (Protein phosphatase 2A), Gdi1 (Guanosine diphosphate dissociation inhibitor 1), Sec61al (Sec61 alpha 


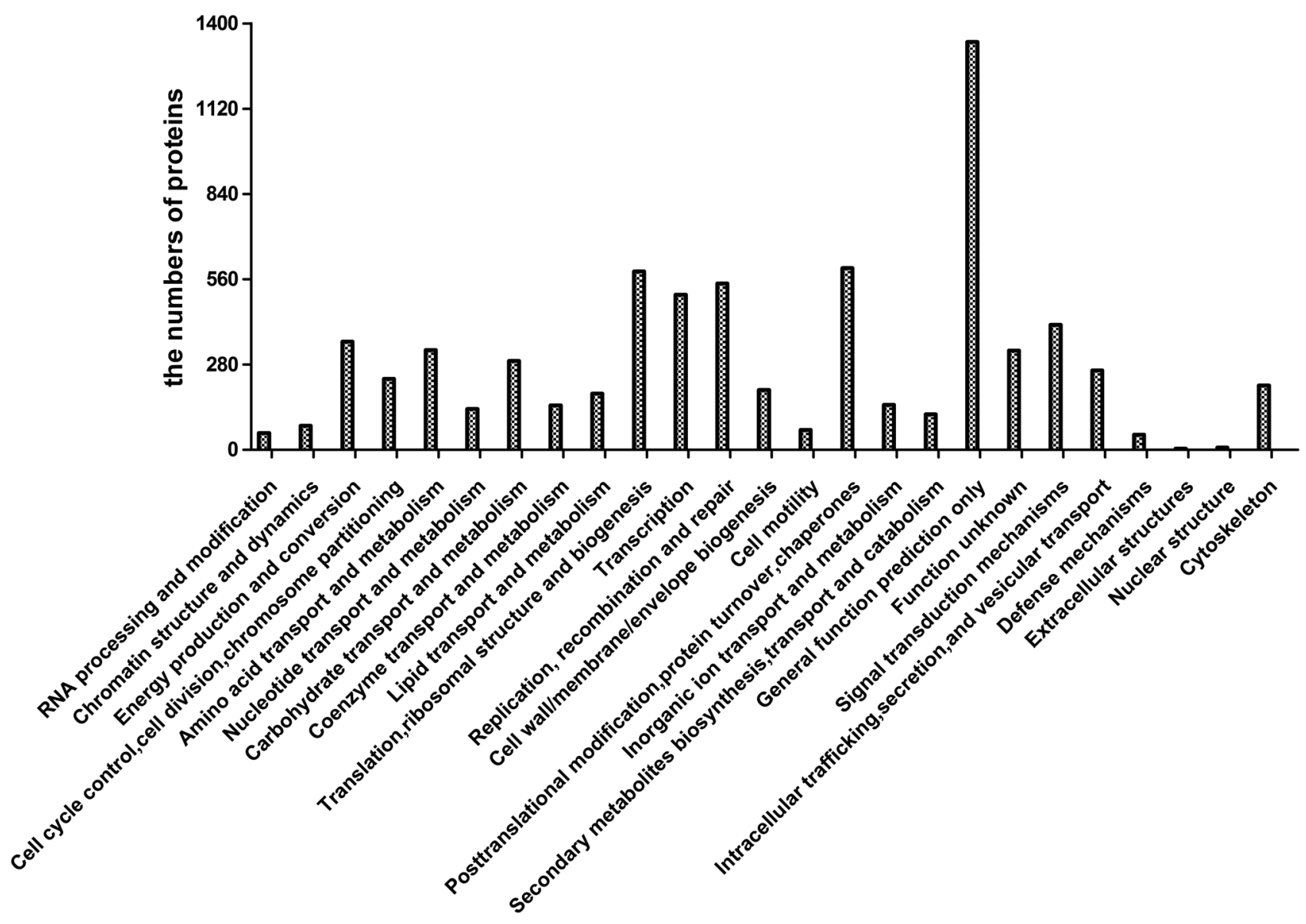

Figure 1. Gene ontology annotations of the proteome of BHK cells infected with Eimeria tenella.

1 subunit), Tm7sf2 (Transmembrane 7 superfamily member 2), Rps8 (Ribosomal protein S8), Mrp120 (Mitochondrial ribosomal protein L20) and Tfrc (Transferrin receptor), with $83 \%$ agreement between the qRT-PCR and iTRAQ results. Results for two proteins did not agree with the iTRAQ data: Ptp4a1 (Protein phosphatase 4, regulatory subunit 1) and Bnip2 (BCL2/adenovirus E1B interacting protein 2) (Table 2). Therefore, taken together these results indicate that most proteins were regulated directly at the transcription level. However, some gene transcript levels did not match the levels of their corresponding proteins, which may indicate that the abundance of the protein may not depend only on the transcript level but also on posttranslational modifications [19]. Additionally, one up-regulated protein (Metastasis associated gene 3, MTA3) and one downregulated protein (Lamin B receptor, LBR) were selected to be analyzed with western blotting. These results confirmed the iTRAQ data, showing that MTA3 was clearly up-regulated in E. tenella-infected cells compared to mock-infected cells, while LBR was down-regulated (Fig. 5).

\section{Discussion}

Although Eimeria sporozoite motility and structural and secreted antigens appear to provide the mechanisms for propelling the sporozoite into the host cell, there is a growing body of evidence that the host cell provides characteristics by which the sporozoites recognize and interact with the host cell as a prelude to invasion [21]. After being infected with Eimeria, the host cells produce a corresponding change to deal with the damage with this infection. In this study, E. tenella-induced modulation of the host cell proteome at 24 hpi was analyzed by iTRAQ coupled with LC-MS/MS. The cell line BHK 21 used in this study has been widely used in Eimeria studies [28] and was better at supporting the growth of E. tenella than primary chicken or turkey cells [1]. The results of proteomic analysis showed that a total of 195 proteins were significantly changed in BHK 21 cells after being infected with E. tenella for $24 \mathrm{hpi}$.

A number of DEPs were predicted to be involved in the host signaling pathway. For instance, SOS1 was up-regulated in host cells infected with $E$. tenella, consistent with previous studies. Xiao et al. found that SOS1 had a significantly higher expression in human epithelial ovarian cancer than normal ovarian tissues and it played a role in promoting Ras activation in the Ras signaling pathway [34]. In contrast, some proteins are downregulated. Concerning menin and collagen alpha-1 (XXVII) chain-like protein (Col24a1) Wu et al. found that reduced menin expression in human lung adenocarcinoma samples is associated with enhanced expression of Ras [33]. 
a

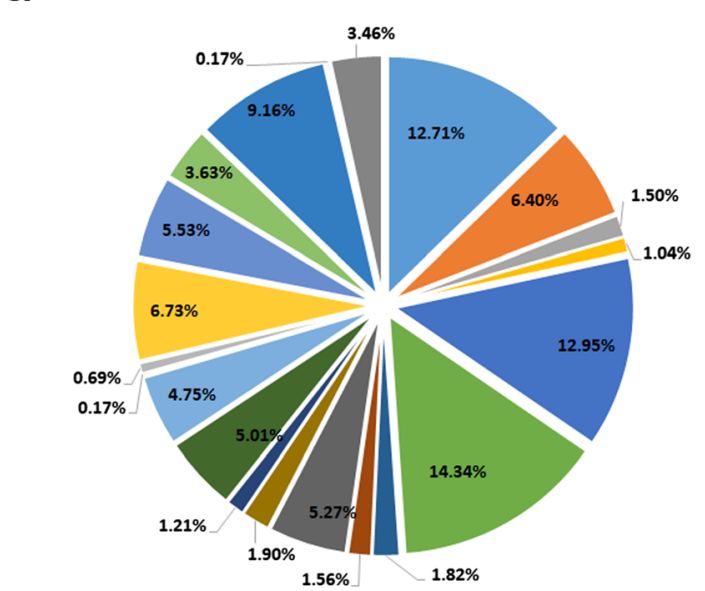

b

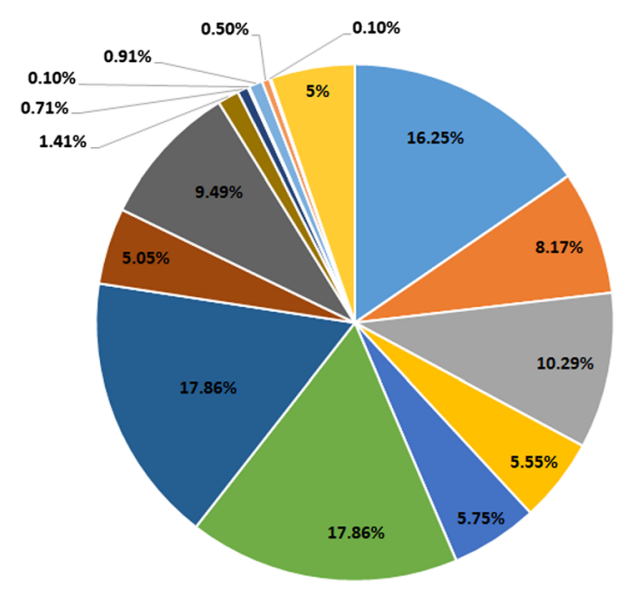

Molecular function

C

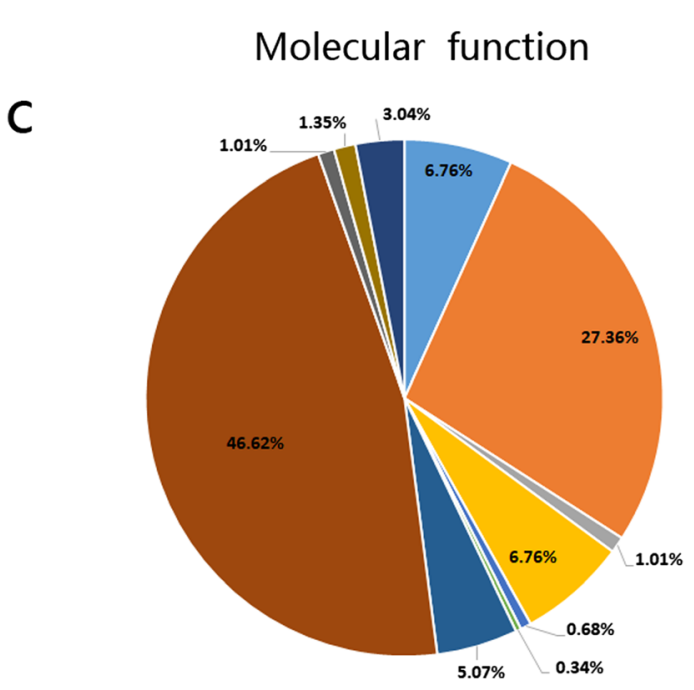

| metabolic process

- cellular component organization or biogenesis - reproductive process

- reproduction

- single-organism process

In cellular process

- multi-organism process

- locomotion

- developmental process

- immune system process

- biological adhesion
- organelle

- macromolecular complex

In organelle part

w extracellular region part

- extracellular region

n cell part

- cell

- membrane-enclosed lumen

- membrane

- cell junction

I synapse part

- nucleoid

= synapse

- extracellular matrix

w extracellular matrix component

membrane part

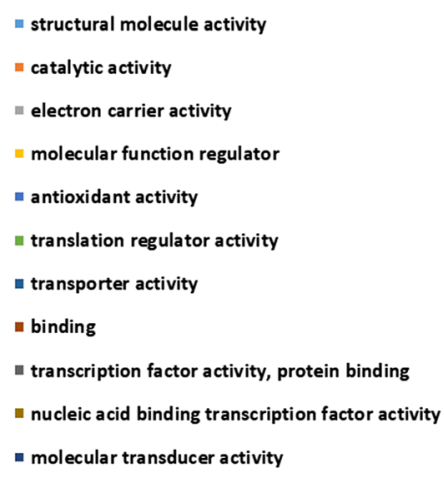

Figure 2. Gene ontology analysis of 195 proteins differentially expressed in BHK cells infected with Eimeria tenella. Proteins were annotated by biological process, cellular component, and molecular function.

These data show that these proteins involved in the Ras signaling pathway play an important role in Eimeria invasion. KEGG analysis showed that the DEPs were also involved in PI3K-Akt, chemokine, and RIG-I receptor-mediated phagocytosis, and the Wnt and p53 signaling pathways. Hence, we predicted that Eimeria binding to the host surface doses not, by itself, 
A
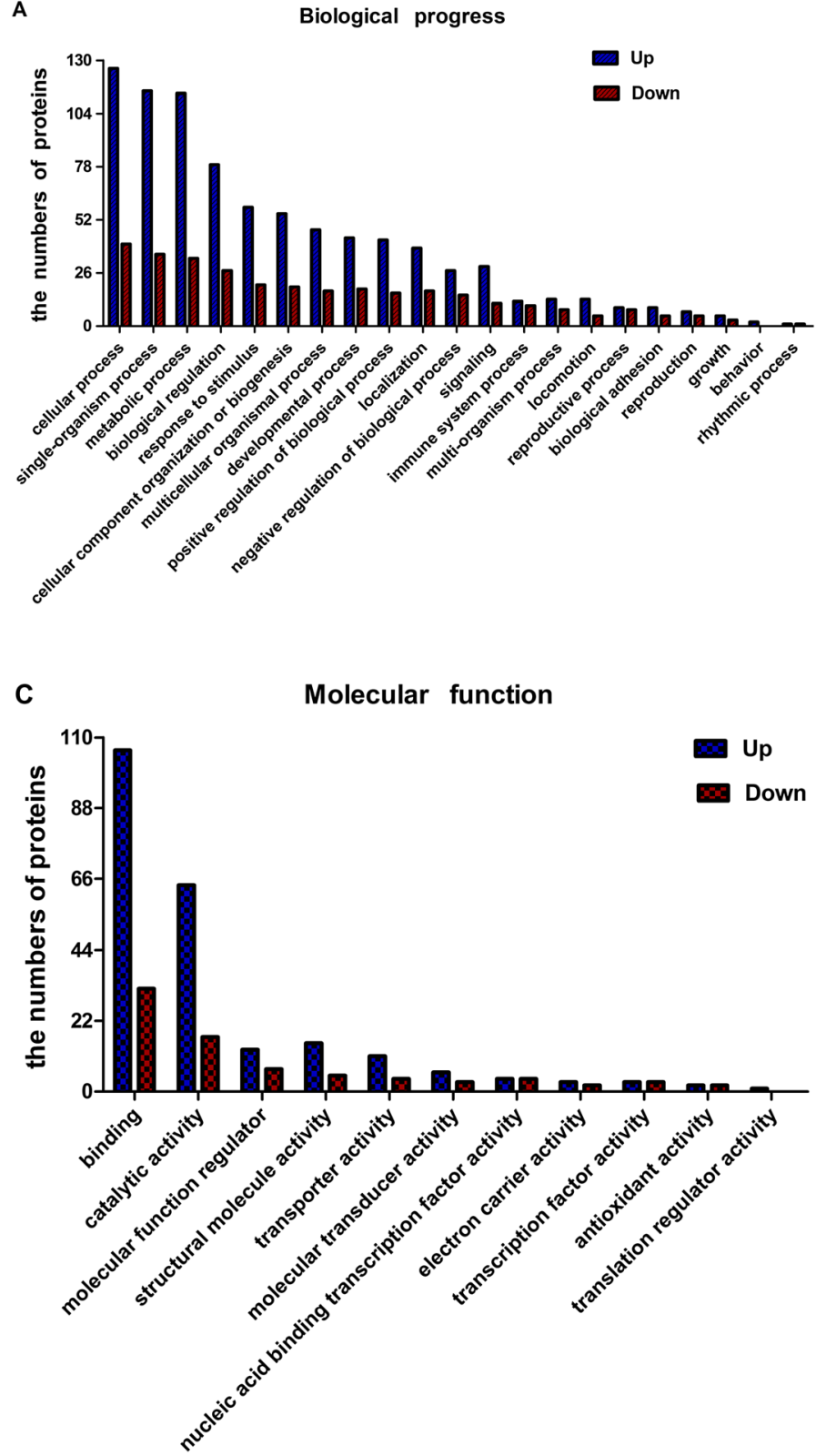

B

Cellular component

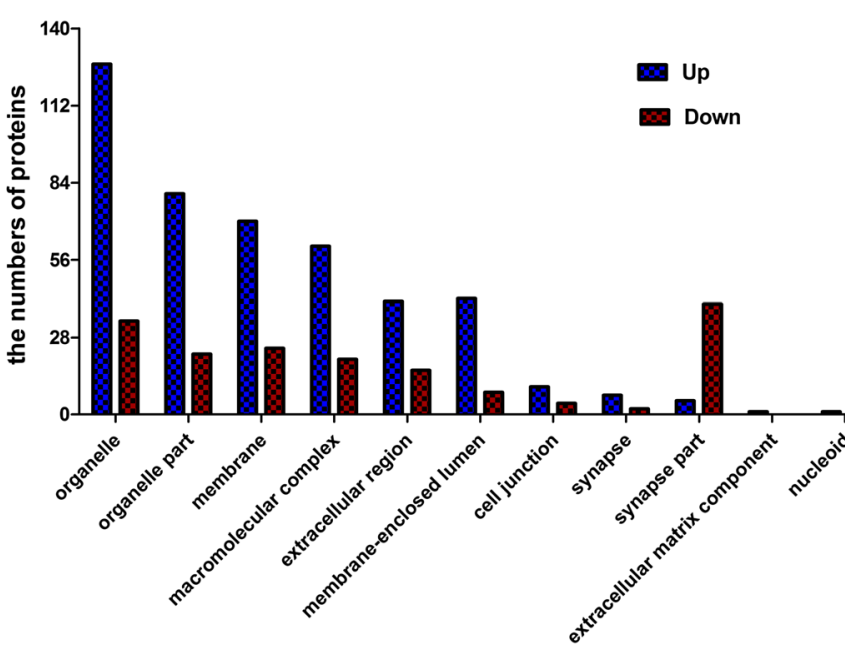

Figure 3. Gene ontology classification of up- and down- regulated proteins in BHK cells infected with Eimeria tenella. Blue bars indicate upregulated proteins, red bars indicate down-regulated proteins.

guarantee access of the parasite into the intracellular environment and may require activation of specific signaling pathways critical for parasite entry into host cells.

It is well known that the intracellular stages of apicomplexan parasites, such as Cryptosporidium parvum [4, 9], Theileria parva [6, 10, 13], Toxoplasma gondii [2, 3, 15], Neospora caninum [8, 17, 18] and Eimeria [5], modulate host cell apoptosis to guarantee successful intracellular development. To date, only a few details are known about the molecular mechanisms allowing for long-term survival of E. tenella within adequate host cells. In this study, a total of 148 DEPs were found to be related to apoptotic pathways. The Frizzled-3 protein $(\mathrm{Fzd} 3)$ is a known transmembrane receptor involved in the secretion of Wnt glycoproteins, important for Wnt signal transduction cascades. Khan et al. found that the activation of the $\mathrm{Wnt} / \beta$-catenin pathway led to altered expression of genes involved in cell cycle regulation and apoptosis in normal and leukemic B-cell progenitors [12]. Additionally, Apoptosisstimulating of p53 protein 2 (TP53BP2) could specifically regulate p53-dependent apoptosis and could be down-regulated with the micro RNA miR-548d-3p by directly targeting the $3^{\prime}$ UTR of the protein, showing that the miR-548d-3p/TP53BP2 pathway is critically involved in the proliferation and apoptosis of breast cancer cells [26]. Concerning our results, Fzd3 
A Statistics of UP-regulated Proteins

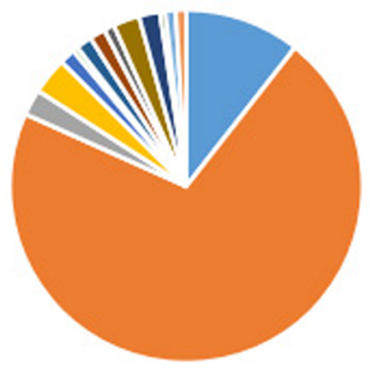

Metabolic pathways

Oxidative phosphorylation

nRNA surveillance pathway

- Cysteine and methionine metabolism

- Proximal tubule bicarbonate reclamation
B Statistics of Down-regulated Proteins

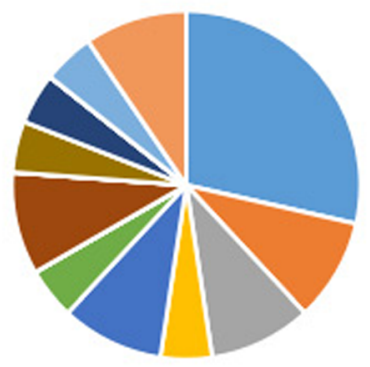

- AMPK signaling pathway

Endometrial cancer

a D-Glutamine and D-glutamate metabolism

n Complement and coagulation cascades

Figure 4. KEGG pathways classification of up- and down- regulated proteins in BHK cells infected with Eimeria tenella, including up-regulated proteins and down-regulated proteins.

Table 2. Fold changes in the mRNA expression of 12 genes differently expressed in BHK cells infected with Eimeria tenella, detected by qPCR.

\begin{tabular}{|c|c|c|c|c|c|c|c|c|c|}
\hline \multirow[b]{2}{*}{ Accession } & \multirow[b]{2}{*}{ Gene name } & \multicolumn{4}{|c|}{ Ratio } & \multicolumn{4}{|c|}{ Ratio } \\
\hline & & iBR1 & iBR2 & iBR3 & Average & qPCR1 & qPCR2 & qPCR3 & Average \\
\hline A0A061ILM3 & Atp51 & 2.940 & 2.786 & 2.879 & 1.63 & 1.04 & 1.05 & 1.09 & 1.06 \\
\hline $\mathrm{A} 0 \mathrm{~A} 1 \mathrm{~A} 6 \mathrm{H} 7 \mathrm{C} 7$ & Mapk9 & 1.382 & 1.388 & 1.374 & 1.38 & 1.98 & 2.13 & 2.13 & 2.08 \\
\hline G3HED1 & Ptp4a1* & 1.300 & 1.358 & 1.273 & $1.31 *$ & 0.24 & 0.36 & 0.30 & $0.30 *$ \\
\hline G3GRN2 & Bnip2* & 3.290 & 3.328 & 3.740 & $3.45^{*}$ & 0.60 & 0.68 & 0.82 & $0.70 *$ \\
\hline A0A061ILM3 & Pdss2 & 2.940 & 2.786 & 2.879 & 2.87 & 1.38 & 1.49 & 1.69 & 1.52 \\
\hline G3II02 & Ppp2r4 & 3.580 & 3.441 & 3.427 & 3.48 & 1.58 & 1.96 & 1.59 & 1.71 \\
\hline A0A061HU28 & Gdi1 & 0.827 & 0.657 & 0.724 & 0.74 & 0.36 & 0.50 & 0.40 & 0.42 \\
\hline G3HIC4 & Sec61a1 & 0.782 & 0.733 & 0.769 & 0.76 & 0.38 & 0.56 & 0.44 & 0.46 \\
\hline G3GRA0 & Tm7sf2 & 0.796 & 0.705 & 0.697 & 0.73 & 0.08 & 0.06 & 0.10 & 0.08 \\
\hline A0A1A6GC37 & Rps8 & 0.706 & 0.755 & 0.824 & 0.76 & 0.50 & 0.55 & 0.48 & 0.51 \\
\hline G3I429 & Mrp120 & 0.771 & 0.797 & 0.731 & 0.76 & 0.58 & 0.66 & 0.80 & 0.68 \\
\hline А0А060BA20 & Tfrc & 0.722 & 0.830 & 0.740 & 0.76 & 0.56 & 0.74 & 0.80 & 0.70 \\
\hline
\end{tabular}

* Expression patterns detected by qRT-PCR were not consistent with those obtained by iTRAQ.

expression was decreased and TP53BP2 was increased in E. tenella-infected cells, and we therefore propose that they could trigger cell apoptosis to defend against Eimeria invasion.

The parasite's successful invasion of a host cell depends entirely on the interaction between the parasite and the host cell membrane. It has been shown that the specific glycoprotein receptor on the erythrocyte surface could recognize Plasmodium falciparum invading cells [16]. In this study, 178 membrane proteins were found to be altered in BHK-21 cells infected with $E$. tenella. These included amino acid transporters (SLC1A1), mitochondrial membrane ATP synthase (ATP51) and cytochrome c oxidase polypeptide 7A1 (COX7A1). It has been found that IL-2 can up-regulate the expression of amino acid transporters such as SLC1A1, which then stimulates natural killer cells to defend against pathogen invasion [11]. Therefore, the identification of these important membraneassociated proteins in this work indicates that membrane proteins contributed to resistance against $E$. tenella infection.

Some DEPs were also predicted to be involved in the host metabolic and stress and defense response, such as apoptosis antagonizing transcription factor (AATF), cyl-CoA, lysophosphatidylglycerol acyltransferase 1 (Lpgat1), platelet-activating factor acetylhydrolase IB subunit beta (Pafah1b2), and acid ceramidase (Asah1). These data indicate that host metabolism was strongly affected after the cells were infected with E. tenella and the cells produced many antimicrobial peptides as part of the innate immune response to defend against E. tenella infection. 


\section{Infection Control}

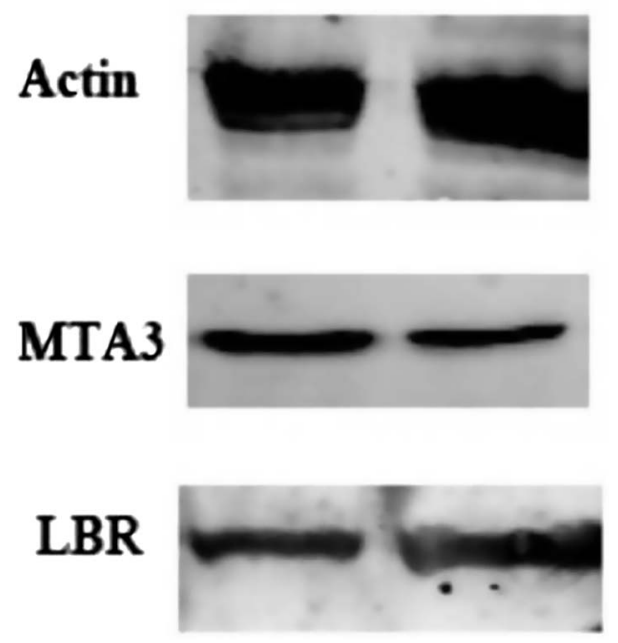

Figure 5. Western blot analysis of MAT3 and LBR in BHK cells infected with Eimeria tenella compared with mock-infected cells.

\section{Conclusion}

To sum up, this is the first attempt to study the proteomic changes in E. tenella-infected BHK-21 cells through an iTRAQ-based proteomic method. Our analyses of the DEPs were comprehensive, but further functional studies are needed to clarify the pathogenic mechanisms and cellular responses to E. tenella infection. This could be important to understand the interaction between the Eimeria parasite and its host cell.

Acknowledgements. This work was supported by grants from the National Key R \& D program of China (No. 2017YFD0500400), National Science Foundation of China (No. 31672551, 31572266) and National Sharing Service Platform for Parasite Resource (No. TDRC - 22). We thank International Science Editing (https:// www.internationalscienceediting.com/) for editing this manuscript. We thank Shanghai Hoogen Biotechnology Co., Ltd for technical assistance.

\section{Competing interests}

The authors declare that they have no competing financial interests.

\section{Supplementary material (Table S1)}

Details list of proteins of BHK cells infected with Eimeria tenella.

Details list of 195 proteins differentially expressed in BHK cells infected with Eimeria tenella.

Supplementary material is available at https://www.parasitejournal.org/10.1051/parasite/2019009/olm

\section{References}

1. Augustine PC. 2001. Cell: sporozoite interactions and invasion by apicomplexan parasites of the genus Eimeria. International Journal for Parasitology, 31, 1-8.
2. Caamano J, Tato C, Cai G, Villegas EN, Speirs K, Craig L, Alexander J, Hunter CA. 2000. Identification of a role for $\mathrm{NF}-\kappa \mathrm{B} 2$ in the regulation of apoptosis and in maintenance of T cell-mediated immunity to Toxoplasma gondii. Journal of Immunology, 165(10), 5720-5728.

3. Carmen JC, Hardi L, Sinai AP. 2006. Toxoplasma gondii inhibits ultraviolet light-induced apoptosis through multiple interactions with the mitochondrion-dependent programmed cell death pathway. Cellular Microbiology, 8(2), 301-315.

4. Chen XM, Levine SA, Splinter PL, Tietz PS, Ganong AL, Jobin C, Gores GL, Paya CV, LaRusso NF. 2000. Cryptosporidium parvum activates nuclear factor kappa B in biliary epithelia preventing epithelial cell apoptosis. Gastroenterology, 120(7), 1774-1783.

5. del Cacho E, Gallego M, Lopez-Bernad F, Quílez J, SánchezAcedo C. 2004. Expression of anti-apoptotic factors in cells parasitized by second-generation schizonts of Eimeria tenella and Eimeria necatrix. Veterinary Parasitology, 125(3-4), 287-300.

6. Dobbelaere DA, Kuenzi P. 2004. The strategies of the Theileria, parasite: a new twist in host-pathogen interactions. Current Opinion in Immunology, 16(4), 524-530.

7. Dong WT, Xiao LF, Hu JJ, Zhao XX, Liu JX, Zhang Y. 2017. iTRAQ proteomic analysis of the interactions between Bombyx mori nuclear polyhedrosis virus and silkworm. Journal of Proteomics, 166, 138-145.

8. Herman RK, Molestina RE, Sinai AP, Howe DK. 2007. The apicomplexan pathogen Neospora caninum inhibits host cell apoptosis in the absence of discernible NF-kappa B activation. Infection \& Immunity, 75(9), 4255-4262.

9. Heussler VT, Küenzi P, Rottenberg S. 2001. Inhibition of apoptosis by intracellular protozoan parasite. International Journal for Parasitology, 31(11), 1166-1176.

10. Heussler VT, Machado JJ, Fernandez PC, Botteron C, Chen CG, Pearse MJ, Dobbelaere DA. 1999. The intracellular parasite Theileria parva protects infected $\mathrm{T}$ cells from apoptosis. Proceedings of the National Academy of Sciences of the United States of America, 96(13), 7312-7317.

11. Jensen H, Potempa M, Gotthardt D, Lanier LL. 2017. Cutting edge: IL-2-induced expression of the amino acid transporters SLC1A5 and CD98 is a prerequisite for NKG2D-mediated activation of human NK cells. Journal of Immunology, 199(6), 1967-1972.

12. Khan NI, Bradstock KF, Bendall LJ. 2007. Activation of Wnt/ $\beta$-catenin pathway mediates growth and survival in B-cell progenitor acute lymphoblastic leukaemia. British Journal of Haematology, 138(3), 338-348.

13. Kuenzi P, Schneider P, Dobbelaere DA. 2003. Theileria parva-transformed $\mathrm{T}$ cells show enhanced resistance to Fas/Fas ligand-induced apoptosis. Journal of Immunology, 171(3), 1224-1231.

14. Lee SH, Lillehoj HS, Jang SI, Kim DK, Ionescu C, Bravo D. 2010. Effect of dietary curcuma, capsicum, and lentinus, on enhancing local immunity against Eimeria acervulina infection. Journal of Poultry Science, 47(1), 89-95.

15. Luder CG, Gross U. 2005. Apoptosis and its modulation during infection with Toxoplasma gondii: molecular mechanisms and role in pathogenesis. Current Topics in Microbiology and Immunology, 289, 219-237.

16. Miller LH, Johnson JG, Schmidtullrich R, Haynes JD, Wallach DF, Carter R. 1980. Determinants on surface proteins of Plasmodium knowlesi merozoites common to Plasmodium falciparum schizonts. Journal of Experimental Medicine, 151 (4), 790-798.

17. Nishikawa Y, Makala L, Otsuka H, Mikami T, Nagasawa H. 2002. Mechanisms of apoptosis in murine fibroblasts by two 
intracellular protozoan parasites, Toxoplasma gondii and Neospora caninum. Parasite Immunology, 24(7), 347-354.

18. Nishikawa Y, Mishima M, Nagasawa H, Igarashi I, Fujisaki K, Otsuka H, Mikami T. 2001. Interferon-gamma-induced apoptosis in host cells infected with Neospora caninum. Parasitology, 123(Pt 1), 25-31.

19. Pradet-Balade B, Boulmé F, Beug H, Müllner EW, GarciaSanz JA. 2001. Translation control: bridging the gap between genomics and proteomics. Trends in Biochemical Sciences, 26(4), 225-229.

20. Ren Y, Hao P, Dutta B, Cheow ES, Sim KH, Gan CS, Lim SK, Sze SK. 2013. Hypoxia modulates A431 cellular pathways association to tumor radioresistance and enhanced migration revealed by comprehensive proteomic and functional studies. Molecular \& Cellular Proteomics, 12, 485-498.

21. Russell DG, Sinden RE. 1981. The role of the cytoskeleton in the motility of coccidian sporozoites. Journal of Cell Science, 50, 345-359.

22. Schmid M, Heitlinger E, Spork S, Mollenkopf HJ, Lucius R, Gupta N. 2013. Eimeria falciformis infection of the mouse caecum identifies opposing roles of IFN $\gamma$-regulated host pathways for the parasite development. Mucosal Immunology, 7(4), 969-982.

23. Schmittgen TD, Livak KJ. 2008. Analyzing real-time PCR data by the comparative $\mathrm{C}(\mathrm{T})$ method. Nature Protocols, 3(6), 1101-1108.

24. Sharman PA, Smith NC, Wallach MG, Katrib M. 2010. Chasing the golden egg: vaccination against poultry coccidiosis. Parasite Immunology, 32(8), 590-598.

25. Shirley MW, Ivens A, Gruber A, Maderia AMBN, Wan KL, Dear PH, Tomely FM. 2004. The Eimeria genome projects: a sequence of events. Trends in Parasitology, 20(5), 199-201.

26. Song Q, Song J, Wang Q, Sun N, Ma J, Chen Q, Xia G, Huo Y, Yang L, Li B. 2016. miR - 548d-3p/TP53BP2 axis regulates the proliferation and apoptosis of breast cancer cells. Cancer Medicine, 5(2), 315-324.

27. Tabarés E, Ferguson D, Clark J, Soon PE, Wan KL, Tomley F. 2004. Eimeria tenella sporozoites and merozoites differentially express glycosylphosphatidylinositol-anchored variant surface proteins. Molecular \& Biochemical Parasitology, 135(1), 123-132.
28. Tierney J, Mulcahy G. 2003. Comparative development of Eimeria tenella (Apicomplexa) in host cells in vitro. Parasitology Research, 90, 301-304.

29. Tomley F. 1997. Techniques for isolation and characterization of apical organelles from Eimeria tenella sporozoites. Methods, 13(2), 171-176.

30. Vermeulen AN. 1998. Progress in recombinant vaccine development against coccidiosis. A review and prospects into the next millennium. International Journal for Parasitology, 28(7), 1121-1130.

31. Wiśniewski JR, Zougman A, Nagaraj N, Mann M. 2009. Universal sample preparation method for proteome analysis. Nature Methods, 6(5), 359-362.

32. Wu CY, Wang Z, Li J, Lin XH, Liao SQ, Qi NS, Lv MN, Sun MF. 2016. A role for host cell F-actin polymerization during the protozoan parasite infection. Chinese Journal of Animal \& Veterinary Sciences, 47(3), 423-428 (in Chinese).

33. Wu Y, Feng ZJ, Gao SB, Matkar S, Xu B, Duan HB, Lin X, Li SH, Hua X, Jin GH. 2012. Interplay between menin and K-Ras in regulating lung adenocarcinoma. Journal of Biological Chemistry, 287(47), 40003-40013.

34. Xiao ZH, Linghu H, Liu QF. 2016. Expressions of Ras and Sos1 in epithelial ovarian cancer tissues and their clinical significance. Journal of Southern Medical University, 36(11), 1502-1507 (in Chinese).

35. Xie MQ, Gilbert JM, Fuller AL, McDougald LR. 1990. A new method for purification of Eimeria tenella merozoites. Parasitology Research, 76(7), 566-569.

36. Zhou ZY, Hu SJ, Wang ZY, Guo ZL, Qin B, Nie K. 2014 Expression of chicken Toll-like receptors and signal adaptors in spleen and cecum of young chickens infected with Eimeria tenella. Journal of Integrative Agriculture, 13(4), 904-910.

37. Zhu C, Zhao Y, Huang X, Pang Y, Zhao Y, He X. 2013. Quantitative proteomic analysis of streptomycin-resistant and sensitive clinical isolates of Mycobacterium tuberculosis. Wei Sheng Wu Xue Bao, 53(2), 154-163 (in Chinese).

38. Zhu M, Dai S, McClung S, Yan X, Chen S. 2009. Functional differentiation of Brassica napus guard cells and mesophyll cells revealed by comparative proteomics. Molecular \& Cellular Proteomics, 8(4), 752-766.

Cite this article as: Zhao Z, Zhao Q, Zhu S, Huang B, Lv L, Chen T, Yan M, Han H \& Dong H. 2019. iTRAQ-based comparative proteomic analysis of cells infected with Eimeria tenella sporozoites. Parasite 26, 7.

Reviews, articles and short notes may be submitted. Fields include, but are not limited to: general, medical and veterinary parasitology: morphology, including ultrastructure; parasite systematics, including entomology, acarology, helminthology and protistology, and molecular analyses; molecular biology and biochemistry; immunology of parasitic diseases; host-parasite relationships; ecology and life history of parasites; epidemiology; therapeutics; new diagnostic tools.

All papers in Parasite are published in English. Manuscripts should have a broad interest and must not have been published or submitted elsewhere. No limit is imposed on the length of manuscripts.

Parasite (open-access) continues Parasite (print and online editions, 1994-2012) and Annales de Parasitologie Humaine et Comparée (1923-1993) and is the official journal of the Société Française de Parasitologie. 